http://dx.doi.org/10.15218/zjms.2014.0025

\title{
Evaluation of immediate loading of single dental implants in the maxillary esthetic zone: Clinical and radiographical comparative study
}

\begin{tabular}{rr}
\hline Serwan Saeb Al Naqshabandi * & Othman Abubakir Omar ** \\
\hline Abstract &
\end{tabular}

Background and objective: Loading an implant right after placement has been attempted and has gained popularity among clinicians. The aim of this study was to evaluate the clinical and radiographical outcomes of immediate loading of single dental implant placed in healed and in fresh extraction sockets.

Methods: In a prospective, comparative, clinical study, 40 patients underwent single dental implant procedure in the maxillary esthetic zone. Twenty implants were placed into fresh extraction sockets (Group A), and the other 20 implants were placed into healed extraction sockets (Group B). Placement of the permanent crown was done within two weeks after implant placement.

Results: From a total of 40 implants only two failed to survive giving a cumulative survival rate of $95 \%$. Both failures occurred in fresh extraction sockets resulting in a survival rate of $90 \%$, while no implant failed in healed sites achieving $100 \%$ survival rate. The difference in marginal bone loss between two groups was statistically significant.

Conclusion: The immediate loading of single dental implant in maxillary esthetic zone is a viable clinical concept and lead to favorable treatment outcomes.

Keywords: Dental, Implants, Maxilla, Esthetic zone.

\section{Introduction}

In the early 1990s, the concept of "immediate loading" was introduced. Today, more than 15 years of clinical and histological investigations have demonstrated its virtues. ${ }^{1,2}$ There is growing scientific evidence showing that osseointegration can be achieved even at implants placed in fresh extraction sockets $^{3}$. Another breakthrough in implant dentistry is the possibility of immediate loading of implants in freshly extracted tooth sockets. ${ }^{4,5}$ The immediate occlusalloading protocol is an implant-supported temporary or definitive restoration in occlusal contact within two weeks of the implant insertion. ${ }^{6}$ Immediate loading of dental implant has gained popularity due to less tissue trauma, reduced overall treatment time, decreased patient's anxiety and discomfort, high patient acceptance and better function and aesthetics. ${ }^{7}$
Therefore, this study could fill in gaps in knowledge about important subject concerning the clinical and radiographical outcomes of immediate loading of single dental implants placed in healed alveolar ridges and fresh extraction sockets in the maxillary esthetic zone.

\section{Methods}

In a prospective, comparative, clinical study 40 patients underwent single dental implant procedure in the maxillary esthetic zone. Twenty implants were placed into fresh extraction sockets (Group A), and the other 20 implants were placed into healed extraction sockets (Group B). All the procedures were carried out in the Department of Oral and Maxillofacial Surgery/College of Dentistry/Hawler Medical University in Erbil, from March 2012 to March 2013.

* Department of oral and maxillofacial surgery, Rezgari teaching hospital, Erbil, Iraq.

** Department of oral and maxillofacial surgery, college of dentistry, Hawler Medical University, Erbil, Iraq. 
http://dx.doi.org/10.15218/zjms.2014.0025

\section{Inclusion criteria were as follow:}

1. Single missing tooth (of at least 6 months post extraction) in maxillary esthetic zone with sufficient residual bone volume (height and width) to receive implants of at least $4.2 \mathrm{~mm}$ in diameter and $12 \mathrm{~mm}$ in length.

2. Presence of a single unrestorable tooth in the maxillary esthetic zone with adequate bone height apically ( $\geq 5 \mathrm{~mm}$ ) to ensure good primary implant stability.

3. Mesial-distal width of inter-dental space at least $7.5 \mathrm{~mm}$

4. Good oral hygiene.

5. Patients with no any systemic disease or active oral disease that might compromise healing or osseointegration.

6. Patient consent.

7. Primary implant stability (insertion torque) should be at least $35 \mathrm{~N} \mathrm{~cm}$.

Surgical technique:

Group A (Implant placement in fresh extraction socket):

The tooth was gently extracted by extraction forceps, with minimum surgical trauma and without any damage to the adjacent soft or hard tissues. Implant placement was performed in the palatal wall of the socket so as to improve primary implant stability and to preserve the labial plate from damage. Drills were used according to the manufacturer's recommendations. In order to obtain primary implant stability of at least $35 \mathrm{~N} \mathrm{~cm}$, which was considered to be a pre requisite for immediate loading in this study, surgical sites were frequently underprepared, then the osteotomy socket was irrigated with normal saline. After that, the implant was manually screwed into osteotomy with the implant driver, until there was a resistance, then the final seating of implant was achieved by torque wrench which was set previously at value $(35 \mathrm{Ncm})$. If the wrench bent before the final seating of the implant, this means the insertion torque reached the value (35 $\mathrm{Ncm}$ ). At that time, we increased the torque value of the wrench into subsequent higher value(s), and then the insertion of the implant was continued and the final torque value was recorded. After that the gingival former was inserted (Figure 1A-B).
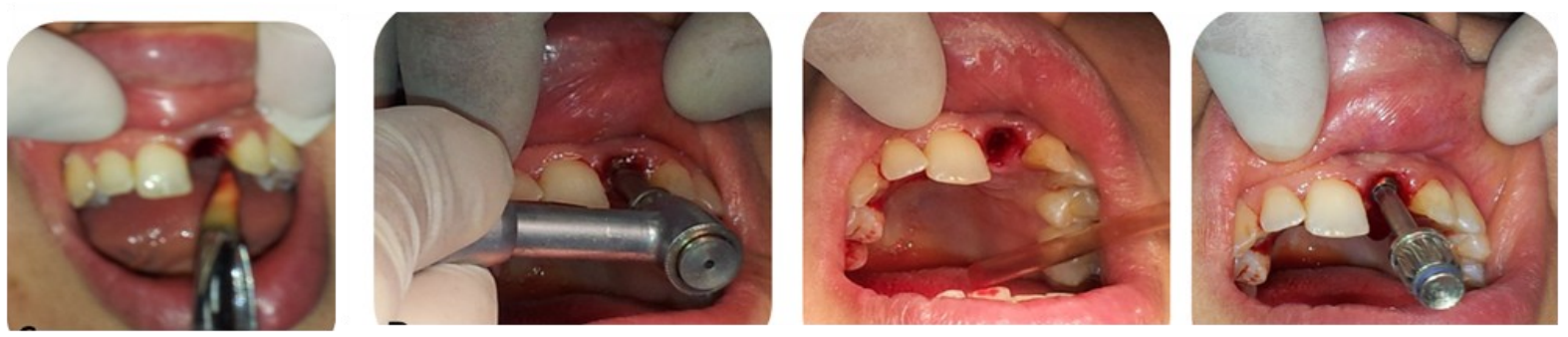

Figure 1A: Unrestorable tooth removed. Implant bed prepared in palatal direction. Implant placed in the prepared bed.
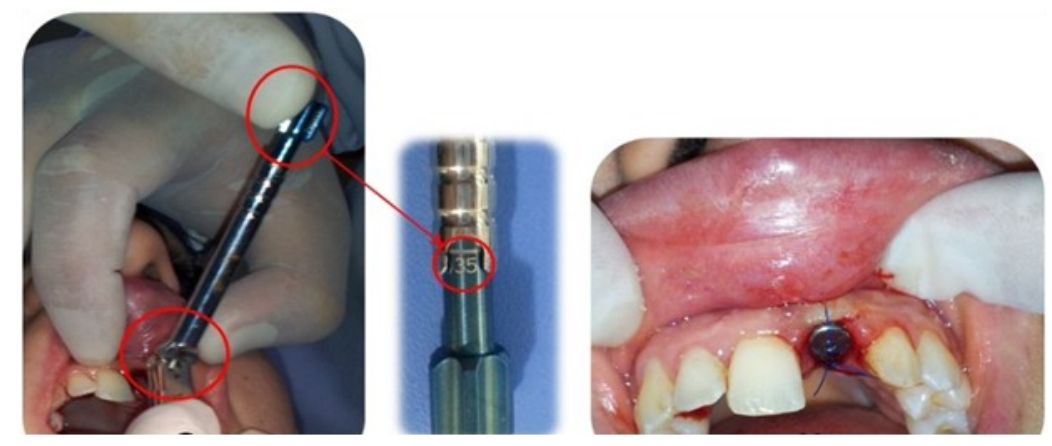

Figure 1 B: Showing implant torque measurment and gingival former placement 
Group B (Implant placement in healed site):

A slightly palatally positioned mini crestal incision was used in order to achieve an optimal soft tissue adaptation and subsequent healing. After that, the same surgical protocol was used as in the group $B$ (Figure 2). Placement of the permanent crown was done within two weeks after implant placement.
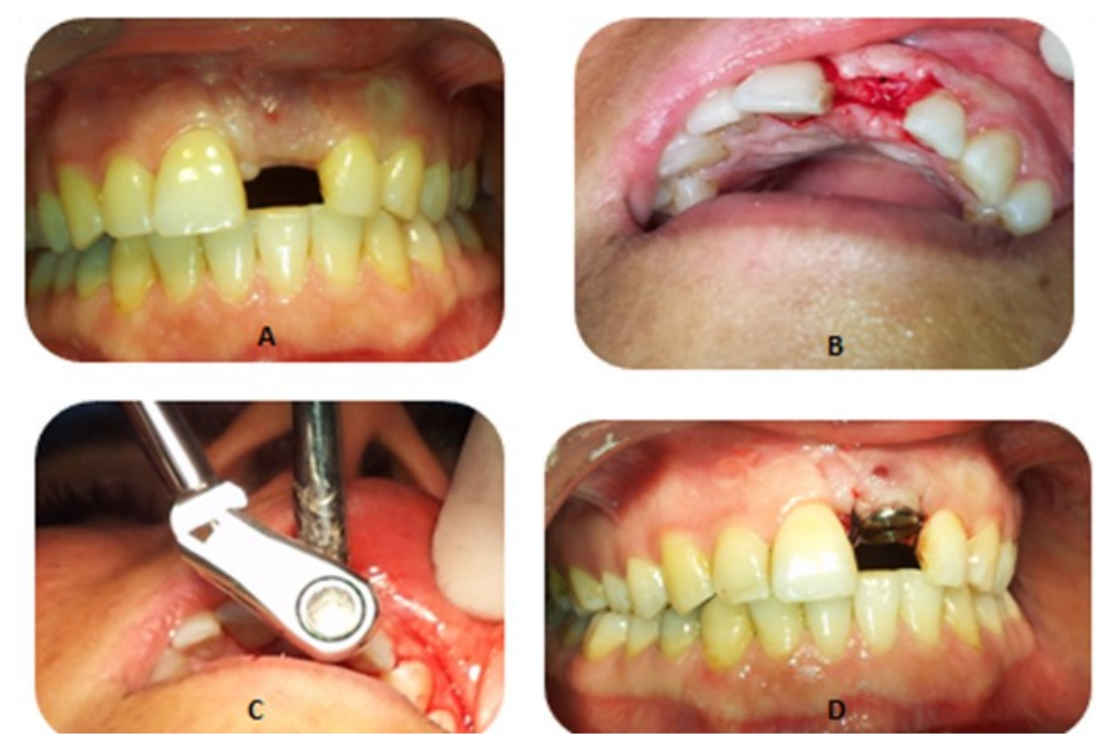

Figure 2: Implant placed in healed alveolus.

\section{Follow up phase}

\section{Clinical Evaluation :}

1. All the patients were examined immediately after surgery and during the first week for the presence of pain, discomfort, swelling or infection.

2. Implant stability was assessed at the delivery of the crown and at 3,6 and 12 months post loading by using two dental instrument handles placed on the buccal and palatal aspect of the crown. ${ }^{8}$

3. Implant survival (defined as the existence of an implant in the oral cavity), ${ }^{9}$ was registered at every follow up.

4. Evaluation of soft tissue around the single tooth implant crown at the end of follow up by using Implant Esthetic Score. ${ }^{10}$

\section{Radiographic Evaluation :}

Direct digital standardized peri-apical radiograph was taken immediately after implant placement, after 3 and 6 months postoperatively. All radiographs were taken using digital system (Planmeca Intra X-ray unit, Finland).

\section{Statistical analysis:}

Data were analyzed using the statistical package for social sciences (SPSS, version 19). Student's t-test was used to compare between two means. Fisher's exact test was used instead of the Chi square test of association when the expected count of more than $20 \%$ of the cells of the row $X$ column table was less than 5. A ' $P$ ' value of $\leq 0.05$ was considered as statistically significant.

\section{Results}

Forty patients participated in the present study. The age of the patients ranged between 19-52 years, with mean age of 32.4 years. Table 1 shows age distribution of the patients. Twenty three patients were males $(57.5 \%)$ and $17(42.5 \%)$ were females. Distribution of implants according to position has been shown in Table 2 . Table 3 shows implant survival rates in both groups. The difference in survival rate between the two groups was not significant 
$(p=0.487)$. The Implant Esthetic Score (IES) showed a significant difference between both groups, Table 4.

Table 1: Distribution of patients according to age groups.

\begin{tabular}{lll}
\hline Age (years) & Number & Percent \\
\hline$<25$ & 12 & 30.0 \\
$25-29$ & 7 & 17.5 \\
$30-34$ & 5 & 12.5 \\
$35-39$ & 6 & 15.0 \\
$\geq 40$ & 10 & 25.0 \\
Total & 40 & 100.0 \\
\hline
\end{tabular}

Table 2: Distribution of implants according to their position.

\begin{tabular}{|c|c|c|c|c|c|c|}
\hline \multirow{3}{*}{ Implant position } & \multicolumn{4}{|c|}{ Group } & \multirow{2}{*}{\multicolumn{2}{|c|}{ Total }} \\
\hline & \multicolumn{2}{|c|}{$\begin{array}{l}\text { Group A } \\
\text { Extraction sites }\end{array}$} & \multicolumn{2}{|c|}{$\begin{array}{l}\text { Group B } \\
\text { Healed sites }\end{array}$} & & \\
\hline & No. & $\%$ & No. & $\%$ & No. & $\%$ \\
\hline Central incisor & 7 & 35.0 & 7 & 35.0 & 14 & 35.0 \\
\hline Lateral incisor & 10 & 50.0 & 4 & 20.0 & 14 & 35.0 \\
\hline Canine & 2 & 10.0 & 5 & 25.0 & 7 & 17.5 \\
\hline First premolar & 1 & 5.0 & 4 & 20.0 & 5 & 12.5 \\
\hline Total & 20 & 100.0 & 20 & 100.0 & 40 & 100.0 \\
\hline
\end{tabular}

Table 3: implant survival in both groups.

\begin{tabular}{lllllll}
\hline \multirow{2}{*}{ Implant outcome } & $\begin{array}{l}\text { Group } \\
\text { Group A }\end{array}$ & & Group B & \multicolumn{3}{c}{ Total } \\
& No. & $\%$ & No. & $\%$ & No. & $\%$ \\
\hline Failure & 2 & 10.0 & 0 & .0 & 2 & 5.0 \\
Survival & 18 & 90.0 & 20 & 100.0 & 38 & 95.0 \\
Total & 20 & 100.0 & 20 & 100.0 & 40 & 100.0 \\
\hline
\end{tabular}

Table 4: mean of IES of both groups and $p$ value.

\begin{tabular}{llllll}
\hline & Group & N & Mean & SD & p value \\
\hline \multirow{2}{*}{ IES } & Group A & 18 & 8.72 & 0.46 & \\
& Group B & 20 & 8.10 & 0.85 & .00812 \\
\hline
\end{tabular}


Evaluation of immediate loading of .......

Zanco J. Med. Sci., Vol. 18, No. (2), 2014

http://dx.doi.org/10.15218/zjms.2014.0025

Regarding marginal bone loss, there was a at 3 months and 6 months after implant significant difference between both groups procedure, Tables 5 and 6 .

Table 5: Marginal bone loss after 3 months.

\begin{tabular}{llcccc}
\hline & Group & No. & Mean & SD & p value \\
\hline $\begin{array}{l}\text { MBL after 3 } \\
\text { months } / \mathrm{mm}\end{array}$ & Group A & 18 & 1.70 & 0.51 & \\
& Group B & 20 & 0.68 & 0.30 & $<0.001$ \\
\hline
\end{tabular}

Table 6: Marginal bone loss after 6 months.

\begin{tabular}{llcccc}
\hline & Group & No. & Mean & SD & p value \\
\hline $\begin{array}{l}\text { MBL after 6 } \\
\text { months } / \mathrm{mm}\end{array}$ & Group A & 18 & 0.84 & 0.23 & 0.002 \\
\hline
\end{tabular}
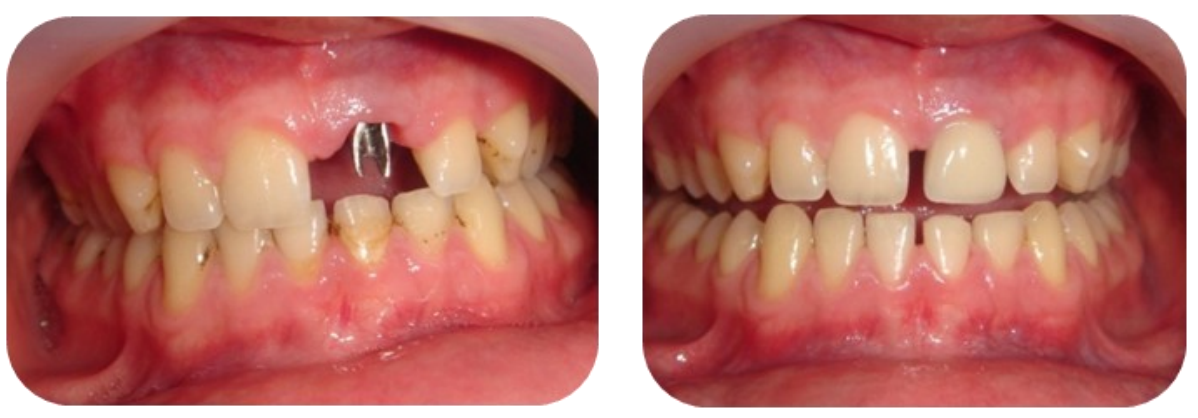

Figure 3: Group A (Implant placement in fresh extraction socket).
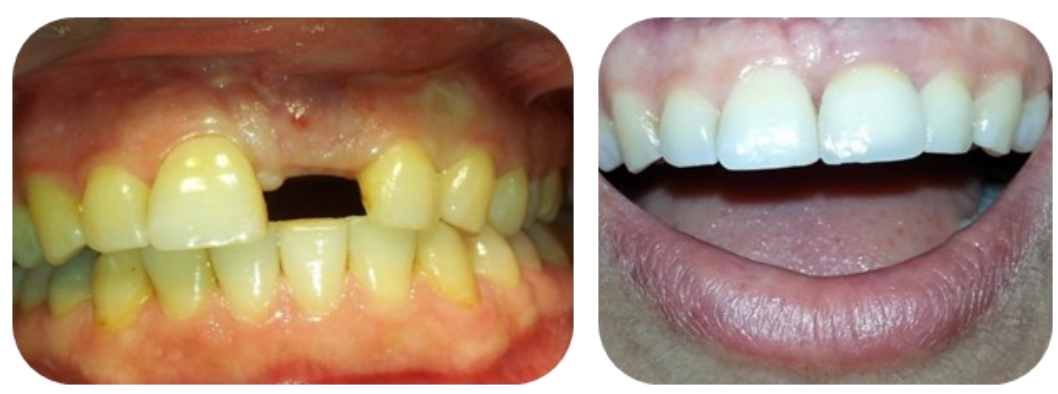

Figure 4: Group B (Implant placement in Healed site) . 


\section{Discussion}

Based on the results of the present study, immediate single implants in the esthetic zone of maxilla may be considered to be a successful treatment strategy with a cumulative implant survival rate of $95 \%$ after 6-12 months of function. This result is comparable to other studies. ${ }^{11-13}$ The high survival rate for immediately loaded implants in healed ridges in the present study was confirmed by other studies. ${ }^{9,13,14}$ According to the literatures, immediate loading of implants placed in fresh extraction sockets revealed survival rates from 82 to $98 \%$, which is comparable to what was found in the present study. ${ }^{15,16}$ This variation may be due to several causes; among them is low bone to implant contact, possible surface contamination, occlusal overloading and low primary stability due to weakness of the buccal plate of bone during extraction. There was statistically significant difference between both groups regarding esthetic results $(P=$ 0.008 ), this was in agreement with other studies, ${ }^{17,18}$ which stated that immediate loading of implants inserted into fresh extraction sockets would lead to more favorable soft tissue levels compared with healed sites. There was minimal or no recession with implants placed in fresh extraction sites which provided good esthetic results. It may be the result of placing the implants without raising a flap and leaving the periosteum intact on the bone, which provides most of the blood supply to the bone. Thereby, when a flap is raised and the periosteum is detached; gingival recession and papillae destruction becomes very prominent as was explained by many authors. ${ }^{19,20}$ The mean $( \pm S D)$ of marginal bone loss in the group A (fresh extraction sites) after the third month of loading was $1.7 \pm 0.51 \mathrm{~mm}$ and decreased to $0.84 \pm 0.23 \mathrm{~mm}$ in the sixth months after loading. These results were also in agreement with a study, ${ }^{21}$ which observed the largest amount of bone loss was in the first three months. Thereafter, diminished loss was observed. In the present study, there was a decrease in vertical marginal bone defect in group A (extraction sites) observed radiographically implying an increase in bone to implant contact. This can be explained due to the fact that healing of the extraction socket proceeds in an apicocoronal direction around the implants. ${ }^{22}$ The mean of marginal bone loss in the group B (healed sites) after the third month (post loading) was $0.68 \pm 0.30 \mathrm{~mm}$ and after the sixth month (post loading) was $0.53+0.31 \mathrm{~mm}$. These values were consistent with what had been reported in other studies on immediate loading of single tooth implants in the esthetic zone. ${ }^{12,18}$

\section{Conclusion}

The immediate loading of single dental implant in maxillary esthetic zone is a viable clinical concept and lead to favorable treatment outcomes.

\section{Conflicts of interest}

The authors report no conflicts of interest.

\section{References}

1. Tarnow DP, Emtiaz S, Classi A. Immediate loading of threaded implants at stage 1 surgery in edentulous arches: ten consecutive case reports with 1- to 5- year data. Int $\mathrm{J}$ Oral Maxillofac Implants 1997; 12: 319-24.

2. Ericsson I, Nilson $H$, Lindh $T$, Nilner K, Randow $\mathrm{K}$. Immediate functional loading of Branemark single tooth implants. An 18 months' clinical pilot follow-up study. Clin Oral Implants Res 2000;11: 26-33.

3. Vanden-Bogaerde L, Rangert B, Eng M, Wendelhag I. Immediate/early function of Branemark system TiUnite implants in fresh extraction sockets in maxillae and posterior mandibles: an 18-month prospective clinical study. Clin Implants Dent Relat Res 2005; 7 (Suppl 1):121-30.

4. Chaushu G, Chaushu S, Tzohar A, Dayan D. Immediate loading of single-tooth implants: immediate versus nonimmediate implantation. A clinical report. Int J Oral Maxillofac Implants 2001; 16:267-72.

5. Kan JY, Rungcharassaeng K, Lozada J. Immediate placement and provisionalization of maxillary anterior single implants: 1-year prospective study. Int J Oral Maxillofac Implants 2003; 18:31-9.

6. Misch CE, Wang $\mathrm{HL}$, Misch CM, Sharawy M, Lemons J, Judy KW. Rationale for the application of immediate load in implant dentistry. J Implant 
Dent 2004; 13 (4): 310-21.

7. Hui E, Chow J, Li D, Liu J, Wat P, Law H. Immediate provisional for single-tooth implant replacement with Branemark system: preliminary report. Clin Implant Dent Relat Res 2001; 3:79-86.

8. Jemt $T$, Lekholm $U$. Implant treatment in edentulous maxilla: a five-year follow-up report on patients with different degrees of jaw resorption. Int J Oral Maxillofac Implants 1991; 10:303-11.

9. Den Hartog L, Raghoebar GM, Stellingsma K, Vissink A, Meijer HJA. Immediate non- occlusal loading of single implants in the aesthetic zone: a randomized clinical trial. J Clin Periodontol 2011; 38: 186-94.

10. Testori T, Bianchi F, Del Fabbro M, Capelli M, Zuffetti F, Berlucchi I, et al . Implant aesthetic score for evaluating the outcome: immediate loading in the aesthetic zone. Pract Proced Aesthet Dent. 2005; 17(2):123-30.

11. Barone A, Rispoli L, Vozza I, Quaranta A, Covani U. Immediate restoration of single implants placed immediately after tooth extraction. J Periodontol 2006; 77: 1914-20.

12. Cooper LF, Raes F, Reside GJ, Garriga JS, Tarrida LG, Wiltfang $\mathrm{J}$, et al. Comparison of radiographic and clinical outcomes following immediate provisionalization of single-tooth dental implants placed in healed alveolar ridges and extraction sockets. Int J Oral Maxillofac Implants 2010; 25(6):1222-32.

13. Raes F, Cosyn J, De Bruyn H. Clinical, Aesthetic, and Patient Related Outcome of Immediately Loaded Single Implants in the Anterior Maxilla: A Prospective Study in Extraction Sockets, Healed Ridges, and Grafted Sites. Clin Implant Dent Res 2012; 17: 1708.

14. Atieh MA, Payne AG, Duncan WJ, Cullinan MP. Immediate restoration/loading of immediately placed single implants: is it an effective bimodal approach? Clin Oral Implants Res 2009; 20: 645-59.

15. Tsirlis AT . Clinical evaluation of immediate loaded upper anterior single implants. Implant Dent 2005; 14:94-103.

16. Ribeiro FS, Pontes AE, Marcantonio E, Piattelli A, Neto RJ, Marcantonio E. Success rate of immediate nonfunctional loaded single-tooth implants: immediate versus delayed implantation. Implant Dent 2008; 17:109-17.

17. De-Rouck T, Collys K, Wyn I, Cosyn J. Instant provisionalization of immediate single-tooth implants is essential to optimize esthetic treatment outcome. Clin Oral Implants Res 2009; 20: $566-70$.

18. Block MS, Mercante DE, Lirette D, Mohamed W, Ryser M, Castellon P. Prospective evaluation of immediate and delayed provisional single tooth restorations. J Oral Maxillofac Surg 2009; 67 (11 Suppl):89-107.
19. Campelo LD, Camara JR. Flapless implant surgery: a 10-year clinical retrospective analysis. Int J Oral Maxillofac Implants 2002;17(2):271-6.

20. Covani U, Barone A, Cornelini R, Crespi R. Soft tissue healing around implants placed immediately after tooth extraction without incision: a clinical report. Int $\mathrm{J}$ oral Maxillofac Implants 2004; 19(4):549-53.

21. De Rouck T, Collys K, Cosyn J. Immediate single -tooth implants in the anterior maxilla: a 1-year case cohort study on hard and soft tissue response. J Clin Periodontol 2008; 35: 649-57.

22. Ten Cate AR, Bartold PM, Squier CA, Nanci A. Oral Histology: Development, Structure and Function. $6^{\text {th }}$ ed. ST. Louis: Mosby Inc; 2003. P. 408. 